Article

\title{
Comparative and Relational Trajectory of Economic Growth and Greenhouse Gas Emission: Coupled or Decoupled?
}

\author{
Taewook Huh (D) \\ Department of Public Administration, Gyeongsang National University, Jinju 52828, Korea; twhuh@gnu.ac.kr \\ Received: 20 April 2020; Accepted: 15 May 2020; Published: 18 May 2020 \\ check for
}

\begin{abstract}
This study looks at the global trajectory of the relationship between GDP (gross domestic product) and $\mathrm{CO}_{2}$ (carbon dioxide) emission in the time-series, comparative, and transitional point of view (from Y1992 to Y2014). It sets up a measurement framework and compares thirty-seven countries (thirty-six OECD countries and China) through the fuzzy-set ideal type analysis while focusing on the comparative and relational types. This research found that economic growth (GDP) and environmental problems $\left(\mathrm{CO}_{2}\right.$ emissions) are tied together in a very solid path-dependent relationship. Particularly, the analysis of comparisons among OECD countries and China shows that the relationship between GDP and $\mathrm{CO}_{2}$ emissions is very firmly coupled, unlike the previous non-combination of one-dimensional statistics that are based on the environmental Kuznets curve (EKC) hypothesis. In short, it draws out and highlights the research implications that the existing conventions regarding the relationship between sustained economic growth and GHG (greenhouse gas) emissions reductions are ill-founded at the international comparative level. This paper reiterates the importance of relevant regulatory policies in order to reduce the harmful external effects of GHG and a need for policy measures to solve the problem in the long term.
\end{abstract}

Keywords: low-carbon economy; $\mathrm{CO}_{2}$ emission; GDP; Fuzzy-set Ideal Type Analysis; international comparative level

\section{Introduction}

We are currently living in a time where a paradigm shift in the global economy is required in order to cope with climate change. This issue is the most urgent and important agenda facing the world in the 21st century. It ultimately indicates that in order to respond to climate change, energy from fossil fuels - the main cause of greenhouse gas (GHG) emissions-should be reduced or replaced, but it also means that the existing economic and social system should be changed from the bottom up [1-3]. The issues of climate change need to be addressed in a way that reflects not only the environmental issues, but also all of the changes in energy, economy, industry, and social systems with a more complex and structured outlook. These are the reasons behind the formation of the concept of a low-carbon economy, particularly originating from sustainable development, as it includes a comprehensive understanding of economy, society, and the environment with climate change issues [4-6].

The term, sustainable development first appeared in the report, called Our Common Future (known as the Brundtland Report), which was published by the World Commission on Environment and Development (WCED) in 1987 [7,8]. After this turning point, there have been active discussions regarding sustainable development globally, and another ground-breaking event was the UN Conference on Environment and Development (UNCED), which was held in Rio de Janeiro in 1992, known as the Rio Conference or the Earth Summit [4,9]. The Rio Conference made sustainable development its main agenda and produced two conventions (the Framework Convention on 
Climate Change and the Convention on Biological Diversity) and three non-binding instruments (the Declaration on Environment and Development Rio Declaration), Agenda 21, and the Statement of Forest Principles [4,10]. As these global efforts continued, the Sustainable Development Summit (WSSD), called "Rio+10", was held in Johannesburg, South Africa in 2002 to commemorate the 10th anniversary of the Rio Environmental Conference.

In terms of global trends, the initial concept of a low-carbon economy was intended to primarily respond to climate change in the context of sustainable development, but it has now been developed into a more comprehensive term, as it now includes the social and economic impacts of climate change $[8,11]$. The idea of the low-carbon economy can be summarized as a term that has both a comprehensive concept for sustainable development and a specific response to climate change $[6,12]$.

Meanwhile, in recent years, the trend toward the decoupling of GHG emissions and economic growth has emerged through European countries and it has drawn attention as a sterling example of improving a country's fundamental economic structure through low-carbonization implementation $[13,14]$. Many studies highlight that the growth of the economy, especially in the western European countries, has been steadily increasing while their GHG emissions have been decreasing $[3,8,15-17]$. These discussions are being used as a basis for sustained economic growth and GHG emissions reductions to be compatible through the transition to a low-carbon economy; and particularly used for the environmental Kuznets curve (EKC) hypothesis: environmental pollution gradual gets worse in the early stage of economic growth, but, if economic development exceeds a certain level, the environmental impact is reduced and it gets cleaned $[12,18,19]$. In particular, the EKC theory that in developed countries, $\mathrm{CO}_{2}$ has an inverted U-shape that decreases after increasing emissions, depending on GDP (gross domestic product) being accepted as significant.

Noting the context of the decoupling of GHG emissions and economic growth, this study aims to examine these discussions on the EKC hypothesis and draw out and highlight the research implications that the accepted conventions regarding the relationship between sustained economic growth and GHG emissions reductions are ill-founded at the international comparative level, through the comparative analysis of 37 cases (OECD countries and China) based on empirical data. The main research questions of this study are as follows:

(a) Does the fuzzy-set ideal type analysis show a relational trajectory of the transition to a global low-carbon economy?

(b) Does the change in the trajectory of a low-carbon economy occur at the time of major international agreements on sustainable development? (Y1992, Y2002, Y2012)?

(c) Does the relationship between GHG $\left(\mathrm{CO}_{2}\right.$ (carbon dioxide)) and economic growth (GDP) appear to be coupled or decoupled?

This research is composed of the following main contents. In Section 2, it argues the theoretical background of sustainable development and climate change along with low carbon economies. In Section 3, it describes the application of the fussy-set analysis methodology and describes the variable composition of the ideal type analysis. In Section 4, it presents the findings of fussy-set ideal type analysis, and finally offers the conclusions and implications in Section 5.

\section{Theoretical Background}

\subsection{Global Efforts for Sustainable Development and Climate Change}

The concept of low-carbon economy is in line with the background of climate change responses, including mitigation, but it has particularly originated from sustainable development. This is because, when the concept of sustainable development was advocated in the 1980s, the main agenda of low-carbon economy focused on the environment, sustainable use of resources, and economic development $[7,8]$. Although three pillars now often represent sustainable development: economy, society, and the environment [4,9], the early idea of climate change tended to only consider 
environmental only. After the Kyoto Protocol was signed, climate change has become an independent and individual agenda beyond the environmental scope until mid-2000s [11].

The United Nations Conference on Environment and Development (UNCED) was held in Rio de Janeiro, Brazil in 1992, and the "Rio Declaration" that contains the principles of sustainable development with its three pillars and its "Agenda 21" action plan were adopted at this conference [4]. Additionally, the United Nations' three major environmental conventions, including the United Nations Framework Convention on Climate Change (UNFCCC), the Convention on Biological Diversity, and the Convention to Combat Desertification were adopted. A decade after the Rio conference, the World Summit of Sustainable Development (WSSD) took place in Johannesburg in 2002 to assess the implementation of performance over the preceding decade and formulate the future implementation plans. The WSSD adopted 'People, Planet and Prosperity' as its priority theme and, thus, emphasizing that the global paradigm on environmental conservation should be transformed from the passive to more active way $[4,11]$.

Since then, the Rio+20 in 2012 focused on the issues related to economic and social development among the three pillars of sustainable development. The Rio+20 addressed not only specific issues regarding the environment, but also a huge paradigm related to the development and some governance issues $[6,11]$.

The international community's recent efforts to address climate change have come to fruition, as the Paris Agreement was adopted at the 21st Conference of the Parties to UNFCCC in 2015, and this provided a turning point for a coordinated global response to climate change [11]. After the Paris Agreement entered into force in November 2016, it reaffirmed the global consensus on responses to climate change and, in doing so, every country should submit their Nationally Determined Contributions (NDCs) to reduce global GHG emissions and implement a new climate regime $[3,11]$. This new regime calls for a shift from a fossil fuel energy-based carbon economy to a low-carbon economy centered on energy technologies, such as energy efficiency and renewable energy. Although it aims to prevent climate change by making fundamental efforts to reduce GHG emissions, its final goal is to realize the low-carbonization of economic system that lowers the dependence on carbon energy, which is the root cause of GHG emissions $[15,20,21]$.

\subsection{Low Carbon Economies: Decoupling of GHG Emissions and Economic Growth}

In 2008, the global economic crisis has triggered making low-carbon economy agendas integrate into economic and social issues [2,22]. In many countries, including the United States, Europe, China, and Japan, their attentions have been increasingly focused on the low-carbon green technologies and industries as a solution to the economic crisis and a new driving force for economic growth, and this showed the potential for the compatibility between climate change measures and economic development $[8,23,24]$. As much of the government spending has been invested in low-carbon energy and green industries, the energy sector as being passive in climate change, also began to consider its technological and economic potential $[3,25]$.

Although there is no clear agreed definition or concept for the low-carbon economy, it is generally referred to as a comprehensive concept for understanding the economic structure and economic system in the context of decarbonization or carbon constraints $[8,12,26]$. The low-carbon economy often tends to be used with interchangeably the terms of green economy, green energy economy, and green growth [2,17]. These similar terms help to systematize the complementary or competitive concepts of low-carbon economy, although each term differs slightly in its agenda, depending on the circumstances [6,8]. Typically, the green economy is an academic concept developed in environmental and resource economics. Sometimes it is understood as available clean resources, and its focus is ultimately on providing concepts, methodologies, and policy measures for sustainable use of resources $[16,27]$. In short, this approach attempts to combine economic growth and environmental sustainability and decouple the process of consumption and waste discharge with economic prosperity $[8,15,28]$. It can be characterized by the theory of the environmental Kuznets curve (EKC). 
However, it is important to recognize that the low-carbonization of economy should be undertaken to bring its radical reform based upon a premise with stable economic growth [2,25]. If GHG reductions act as an impediment to economic growth, social costs due to economic stagnation may arise, which makes it difficult to secure the necessary justification. In fact, the traditional view on the relevance between economic growth and GHG emissions is that economic growth will inevitably entail GHG emissions $[3,17]$. Economic growth will lead to increased energy demand, and this increased energy demand will be covered through the use of relatively inexpensive fossil fuel energy. Additionally, the preference for convenience due to economic growth will lead to an increase in demand for network energy (electricity, city gas, etc.). This increase in demand for network energy is accompanied by conversion losses in the transformation process, which leads to an additional increase in energy demand for primary energy [22,24].

As a result, apart from global consensus on responding to climate change, there are still strong positions that GHG reduction can hinder economic growth [14,25]. In the process of negotiations under UNFCCC, although developed countries emphasized the necessity of global participation in GHG reductions, many of these countries were not active in practical emissions reduction initiatives $[11,20]$. The superpower, the United States, has refused to ratify the Kyoto Protocol, regarding its adverse impact on its economy, and it has declared its intention to withdraw from the Paris Agreement.

However, there are also a number of studies showing the relevance between economic growth and GHG emissions has weakened, especially in developed countries $[19,22,25]$. The emphasis is placed on the fact that economic growth, especially in Western Europe and Nordic countries, has been steadily increasing, while GHG emissions were decreasing [25,28]. Even though the United States has a record of a steady increase in GHG emissions, but its emissions have begun decrease [8]. The International Energy Agency (IEA) estimates that global GHG emissions have been stagnant since mid-2010, while GDP continues to grow $[15,20]$. This suggests that economic growth and GHG reductions are compatible, and there is a growing interest in economic growth and decoupling of GHG emissions.

The decoupling of GHG emissions and economic growth implies the decrease in GHG emissions as the economy continues to grow [14]. Several studies have suggested the concepts of absolute decoupling and relative decoupling, where the former means that GDP grows but GHG emissions decline, and the latter represents the improvement of emission intensity, although in general, decoupling means "absolute decoupling" $[8,17,25]$. However, there is some indication that the term "de-coupling" is somewhat confusing, given that it is difficult to completely separate the correlation between economic growth and GHG emissions.

This decoupling term is not a result of academic discussion, but rather a term that was created to explain the phenomenon that was observed in the real world. As a result, the correlation between economic growth and GHG emissions has been weakened, and the transition to a low-carbon economy has been used as a logic that sustainable economic growth and GHG reduction can be compatible [12,17]. Accordingly, the context of the decoupling of GHG, specifically $\mathrm{CO}_{2}$ and economic growth is a crucial part, but it should be noted that decoupling will remain a mere slogan unless there is a thorough review of the context in which it is being achieved.

\section{Methodology and Measurement Framework}

This study takes the methodology of fuzzy-set analysis. It is a special form of qualitative comparative analysis $[29,30]$ developed by Lofti Zadeh, and also used in diverse ways by scholars, such as Charles Ragin and Jon Kvist in the social sciences [31,32]. Fuzzy set analysis goes beyond the traditional two membership scores of 1 or 0 that characterizes crisp sets and makes use of various membership scores between 0 and 1 that can document not only partial memberships, but also the difference of the grade.

The following main advantages characterized the fuzzy-set analysis. First, disadvantages of variable-oriented and case-oriented studies can be eliminated by applying the fuzzy-set methodology. The fuzzy-set analysis categorizes cases by combining two strategies: variable-oriented quantitative 
methods and qualitative case studies [29,31]. Second, the fuzzy-set analysis makes middle-class (15-50 cases) comparative analysis possible, unlike both (qualitative) comparative case analysis and (quantitative) regression analysis $[30,33,34]$. Third, the fuzzy-set analysis can interpret diverse social phenomena by overcoming the dichotomy method of 0 and 1 , used in the existing social science studies. It enhances the representation of continuous degrees between the ' 0 ' and ' 1 ', which minimizes the loss of information in analysis [35,36]. Fourth, the fuzzy-set analysis enables a more theoretical approach to categorization of types by determining the number of memberships and categorizing the standards, based on the theoretical background [32].

This study categorizes and compares thirty-seven case countries by making use of the fuzzy-set ideal type analysis. It applies the theory of fuzzy-set to explain how close the subject of analysis is to that which is turned into fuzzy sets $[35,36]$. Through this process, it analyzes the grade of memberships of each category, converting the original data into fuzzy-set membership scores. This paper produces a more systematic categorization and interpretation results, as the ideal type determines the number of the sets, differentiating fuzzy-set analysis from the existing statistical method, such as the cluster analysis $[34,37]$.

In particular, as this study calibrated the data into fuzzy-set membership score through the function of STATA 12.0, this research has measured them based on the main qualitative anchors (cornerstones): 'fully in', 'fully out', and 'crossover point'. Namely, any score that is higher than the crossover point (0.5) is given strong membership (FI: fully in or full membership), and any score below the crossover point is given low membership score (FO: fully out or full non-membership). The formula for measuring the Degree of Membership Score in the fuzzy-set ideal type analysis is as follows:

$$
\text { Degree of Membership }=\exp (\log \text { odds }) /(1+\exp (\log \text { odds }) .
$$

This research first sets up the two type categories and two variables in order to carry out the fuzzy set ideal type analysis (see Table 1 below). Second, it translated (calibrated) the two type variables into fuzzy scores by using the three cornerstones (minimum, median [p50], and maximum of the origin values), respectively, in order to identify the types of link between Greenhouse Gas Emission and Economic Growth in all thirty-six OECD countries and China from Y1992 to Y2014 - the most recent year in which data from all 37 case countries are valid.

For the variable framework, $\mathrm{CO}_{2}$ emissions (kiloton (kt), all emissions in the country) and (nominal) GDP (millions, USD, expenditure approach, current prices, current PPPs (purchasing power parity)) were selected and constituted the variable framework of this study. For example, the Kyoto Protocol regulated the six major greenhouse gases: carbon dioxide $\left(\mathrm{CO}_{2}\right)$, methane $(\mathrm{CH} 4)$, nitrous oxide $\left(\mathrm{N}_{2} \mathrm{O}\right)$, hydrogen fluoride (HFCs), perfluorinated carbon (PFCs), and sulfur hexafluoride (SF6). Of these, carbon dioxide $\left(\mathrm{CO}_{2}\right)$ accounts for the highest share of about $90 \%$. In addition, GDP (gross domestic product) is the sum of income that is generated within a country's territory. It indicates that various economic actors actually affect people's lives through production activities. In this study, economic growth is not understood as a growth rate that represents an increase in goods and services produced in a specific country, but rather economic growth is grasped in total through GDP, which is an important indicator of a nation's economic power. This study has selected GDP as a quantitative unit in the same sense as $\mathrm{CO}_{2}$ emissions. They $\left(\mathrm{CO}_{2}\right.$ and GDP) are from the statistics of the World Bank Group and OECD, respectively.

This research calculated and interpreted the degree of membership of the fuzzy-set ideal type analysis while using the negation principle, the minimum principle, and the maximum principle $[29,33]$. Setting the two category variables (' $\mathrm{CO}_{2}$ emissions' (C) and 'GDP' $(\mathrm{G})$ ), this study used the principle of negation to establish ' $\mathrm{c}$ ' and ' $\mathrm{g}$ ' as negative categories of the two category variables ' $\mathrm{C}$ ' and ' $\mathrm{G}$ ' through a fuzzy set membership score of 1 in each of the applicable categories. Accordingly, the ideal type was decided by applying number of cases that each category variable can adopt. It postulates four ideal type sets (high or low) based on the four category variables, as shown in Table 2. 
Table 1. The Variable Framework of the Fuzzy-set Ideal Type Analysis.

\begin{tabular}{cccc}
\hline & Categories & Variables & References (Year) \\
\hline C & Greenhouse Gas Emission & $\mathrm{CO}_{2}$ emissions (kt) & World Bank Group \\
& & & $(1992,2002,2012,2014)[38]$ \\
G & Economic Growth & GDP (millions, USD) & OECD \\
& & & $(1992,2002,2012,2014)[39]$ \\
\hline
\end{tabular}

Table 2. The Four Ideal Type Sets.

\begin{tabular}{cc}
\hline Ideal Type & Features of Types \\
\hline 1: $\mathrm{C}^{*} \mathrm{G}$ & High $\mathrm{CO}_{2}$ Emission \& High Economic Growth \\
\hline 2: $\mathbf{C}^{*} \mathbf{g}$ & High $\mathrm{CO}_{2}$ Emission \& low economic growth \\
\hline 3: $\mathbf{c}^{*} \mathrm{G}$ & low $\mathrm{CO}_{2}$ emission \& High Economic Growth \\
\hline 4: $\mathbf{c}^{*} \mathbf{g}$ & low $\mathrm{CO}_{2}$ emission \& low economic growth \\
\hline
\end{tabular}

The four ideal type sets were created and explained by both principles of minimum and maximum $[35,40]$. The minimum principle means that the minimum value (scores) among the fuzzy set scores derived from the four types of ideal type categorization will constitute the fuzzy set membership score of the respective categories; namely, among the fuzzy scores of the two variables $(C, G)$ that constitute category sets, the minimum value was selected. For instance, the fuzzy set member ship score of category $C^{*} G$ is indicated as the fuzzy score of $C$ itself if the fuzzy score of $C$ in category $C^{*} \mathrm{G}$ appears to be the minimum value. The maximum principle describes that while four types of categories can conclusively present the fuzzy-set membership score of 37 countries, the one with the maximum value of the membership scores will be the category for the equivalent area.

\section{Findings of Fussy-Set Ideal Type Analysis}

The changes in the $\mathrm{CO}_{2}$ emission and GDP of the 37 case countries are shown in the descriptive statistics, as described in Table 3 below. From Y1992 to Y2012, the $\mathrm{CO}_{2}$ emissions (mean value) continued to rise (increased to $17.8 \%$ in 2002 (annual average increase of 1.78\%), 33.7\% in 2012 (annual average increase of $3.37 \%)$ ), but after 2012, the upward trend appears to have been shaky $(0.58 \%$ in 2014 (annual average increase of $0.29 \%$ )). Additionally, the median value (p50) of $\mathrm{CO}_{2}$ emissions declined for the first time in 2014 (from 80,043.3 kt to 67,318.8 kt). In addition, GDP has increased by $69.5 \%$ in 2002 (annual average increase of about $6.95 \%$ ), 73.5\% in 2012 (annual average increase of about 7.35\%), $10.7 \%$ in 2014 (annual average increase of 5.35\%), over a period of 22 years.

Table 3. Descriptive Statistics of the 37 Case Countries.

\begin{tabular}{ccccccccc}
\hline \multirow{2}{*}{ Year } & \multicolumn{3}{c}{ CO $_{2}$ Emissions (kt) } & \multicolumn{3}{c}{ GDP (million USD) } \\
\cline { 2 - 9 } & Mean & Min & p50 & Max & Mean & Min & p50 & Max \\
\hline 1992 & $382,964.1$ & 1818.8 & $60,395.5$ & $4,909,534$ & $575,504.7$ & 5711.9 & $166,690.6$ & $6,520,327$ \\
\hline 2002 & $451,038.3$ & 2170.9 & $67,073.1$ & $5,641,309$ & $975,658.1$ & 9351.4 & $251,984.8$ & $10,936,418$ \\
\hline 2012 & $603,077.4$ & 1800.5 & $80,043.3$ & $10,028,573.9$ & $1,693,032.2$ & $13,446.5$ & $391,635.2$ & $16,197,007$ \\
\hline 2014 & $606,568.6$ & 1983.8 & $67,318.8$ & $10,291,926.9$ & $1,874,851.8$ & $14,966.4$ & $417,059.5$ & $18,259,747$ \\
\hline
\end{tabular}

Through the fuzzy-set ideal type analysis, the four ideal types (sets) with the arrangement of the two variables (' $\mathrm{CO}_{2}$ emissions' (C) and 'GDP' $(\mathrm{G})$ ) are derived from the thirty-seven countries. Tables 4 and 5 below show the results of the fuzzy membership scores (fuzzy score) of the thirty-seven case countries for $\mathrm{CO}_{2}$ emissions $(\mathrm{C})$ and GDP $(\mathrm{G})$ - the representative results in $\mathrm{Y} 1992$ and $\mathrm{Y} 2014$ - the selected fuzzy set score for each country in the shaded cells below. 
Table 4. Results of Fuzzy-set Ideal Type Analysis (Y1992).

\begin{tabular}{|c|c|c|c|c|c|c|c|}
\hline Type & $\mathrm{CO}_{2}$ Emissions & GDP Fuzzy & 1 & 2 & 3 & 4 & \multirow[t]{2}{*}{ Ideal Type } \\
\hline Country & Fuzzy Score & Score & $\mathrm{E}^{*} \mathrm{~S}^{*} \mathrm{~T}$ & $E^{*} S^{*} t$ & $E^{*} s^{*} T$ & $E^{*} s^{*} t$ & \\
\hline USA & 0.953 & 0.953 & 0.953 & 0.047 & 0.047 & 0.047 & \multirow{16}{*}{$\begin{array}{c}\text { Type 1: } \\
\mathrm{C}^{*} \mathrm{G}\end{array}$} \\
\hline JPN & 0.659 & 0.765 & 0.659 & 0.235 & 0.341 & 0.235 & \\
\hline $\mathrm{CHN}$ & 0.836 & 0.650 & 0.650 & 0.350 & 0.164 & 0.164 & \\
\hline DEU & 0.626 & 0.678 & 0.626 & 0.322 & 0.374 & 0.322 & \\
\hline GBR & 0.576 & 0.598 & 0.576 & 0.402 & 0.424 & 0.402 & \\
\hline ITA & 0.555 & 0.613 & 0.555 & 0.387 & 0.445 & 0.387 & \\
\hline CAN & 0.559 & 0.549 & 0.549 & 0.451 & 0.441 & 0.441 & \\
\hline FRA & 0.547 & 0.610 & 0.547 & 0.390 & 0.453 & 0.390 & \\
\hline MEX & 0.542 & 0.564 & 0.542 & 0.436 & 0.458 & 0.436 & \\
\hline KOR & 0.535 & 0.532 & 0.532 & 0.468 & 0.465 & 0.465 & \\
\hline ESP & 0.527 & 0.549 & 0.527 & 0.451 & 0.473 & 0.451 & \\
\hline AUS & 0.532 & 0.520 & 0.520 & 0.480 & 0.468 & 0.468 & \\
\hline NLD & 0.516 & 0.518 & 0.516 & 0.482 & 0.484 & 0.482 & \\
\hline TUR & 0.514 & 0.541 & 0.514 & 0.459 & 0.486 & 0.459 & \\
\hline POL & 0.545 & 0.508 & 0.508 & 0.492 & 0.455 & 0.455 & \\
\hline BEL & 0.508 & 0.504 & 0.504 & 0.496 & 0.492 & 0.492 & \\
\hline $\mathrm{CZE}$ & 0.512 & 0.302 & 0.302 & 0.512 & 0.302 & 0.488 & \multirow{2}{*}{$\begin{array}{c}\text { Type 2: } \\
\mathrm{C}^{*} \mathrm{~g} \\
\end{array}$} \\
\hline GRC & 0.502 & 0.417 & 0.417 & 0.502 & 0.417 & 0.498 & \\
\hline $\mathrm{CHE}$ & 0.289 & 0.503 & 0.289 & 0.289 & 0.503 & 0.497 & \multirow{2}{*}{$\begin{array}{c}\text { Type } 3 \\
\mathrm{c}^{*} \mathrm{G} \\
\end{array}$} \\
\hline SWE & 0.382 & 0.501 & 0.382 & 0.382 & 0.501 & 0.499 & \\
\hline ISL & 0.047 & 0.047 & 0.047 & 0.047 & 0.047 & 0.953 & \multirow{15}{*}{$\begin{array}{c}\text { Type } 4 \\
\text { c* }^{*}\end{array}$} \\
\hline LUX & 0.072 & 0.054 & 0.054 & 0.072 & 0.054 & 0.928 & \\
\hline SVN & 0.079 & 0.064 & 0.064 & 0.079 & 0.064 & 0.921 & \\
\hline LVA * & 0.086 & 0.056 & 0.056 & 0.086 & 0.056 & 0.914 & \\
\hline LTU ** & 0.124 & 0.063 & 0.063 & 0.124 & 0.063 & 0.876 & \\
\hline EST *** & 0.134 & 0.050 & 0.050 & 0.134 & 0.050 & 0.866 & \\
\hline NZL & 0.141 & 0.107 & 0.107 & 0.141 & 0.107 & 0.859 & \\
\hline IRL & 0.182 & 0.109 & 0.109 & 0.182 & 0.109 & 0.818 & \\
\hline NOR & 0.189 & 0.188 & 0.188 & 0.189 & 0.188 & 0.811 & \\
\hline CHL & 0.193 & 0.166 & 0.166 & 0.193 & 0.166 & 0.807 & \\
\hline ISR & 0.289 & 0.184 & 0.184 & 0.289 & 0.184 & 0.711 & \\
\hline SVK & 0.304 & 0.083 & 0.083 & 0.304 & 0.083 & 0.696 & \\
\hline FIN & 0.340 & 0.185 & 0.185 & 0.340 & 0.185 & 0.660 & \\
\hline PRT & 0.350 & 0.340 & 0.340 & 0.350 & 0.340 & 0.650 & \\
\hline DNK & 0.423 & 0.232 & 0.232 & 0.423 & 0.232 & 0.577 & \\
\hline HUN & 0.500 & 0.180 & 0.180 & 0.500 & 0.180 & 0.500 & Type $2 \& 4$ \\
\hline AUT & 0.452 & 0.500 & 0.452 & 0.452 & 0.500 & 0.500 & Type $3 \& 4$ \\
\hline
\end{tabular}

The findings on the link between $\mathrm{CO}_{2}$ emissions and GDP for each of the thirty-seven case countries are very similar over a period of 22 years. Figures 1-4, below, show the continuity and results of the ideal types for each country. This study reveals that, except for four countries (Austria, Chile, Greece, and Hungary), the ideal types of the remaining 33 countries have never changed from Y1992 to Y2014.

In particular, the sixteen countries of Type $1\left(\mathrm{C}^{*} \mathrm{G}\right.$ : high $\mathrm{CO}_{2}$ emission and GDP) have remained unchanged for 22 years. For example, USA (fuzzy membership score 0.953), Japan (0.659), China (0.650), Germany (0.626) in 1992; USA (0.953), China (0.770), Japan (0.650), Germany (0.601) in 2002; China (0.944), USA (0.820), Japan (0.586), Germany (0.556) in 2012; and, China (0.953), USA (0.821), Japan (0.583), Germany (0.548) in 2014. Meanwhile, only in the United Kingdom, the ranking changed from fifth in Y1992 and Y2002 to eighth in Y2012 and Y2014 (CO emissions have improved relative to other countries), but the ranking of the rest of the Type 1 countries remained almost unchanged.

There were fifteen countries that belonged to Type 4 ( $c^{*}$ g: low $\mathrm{CO}_{2}$ emission and GDP) and remained the same for 22 years. For example, Israel (fuzzy membership score 0.953), Luxemburg (0.928), Slovenia 
(0.921) in Y1992; Israel (0.953), Latvia (0.942), Luxemburg (0.935), Lithuania (0.924), Estonia (0.918) in Y2002; Israel (0.953), Latvia (0.941), Luxemburg (0.935), Lithuania (0.926), Slovenia (0.924) in Y2012; Israel (0.953), Latvia (0.940), Luxemburg (0.934), Slovenia (0.924), and Lithuania (0.924) in Y2014.

Type $2\left({ }^{*} \mathrm{G}\right)$, which has low $\mathrm{CO}_{2}$ emission and high GDP, had only three countries (Czech Republic, Greece, and Chile) for 22 years. In particular, the Czech Republic has been affiliated with this group for 22 years. Additionally, only two countries (Switzerland and Sweden) belonged to Type 3 (C $C^{*}$ : high $\mathrm{CO}_{2}$ emission and low GDP) and remained unchanged for 22 years. On the other hand, countries with a fuzzy score of 0.500 that do not belong to any type were analyzed as Austria, Hungary in Y1992, Austria in Y 2002, Chile and Greece in Y2012, and Austria and Greece in Y2014.

Table 5. Results of Fuzzy-set Ideal Type Analysis (Y2014).

\begin{tabular}{|c|c|c|c|c|c|c|c|}
\hline Type & $\mathrm{CO}_{2}$ Emissions & GDP Fuzzy & 1 & 2 & 3 & 4 & \multirow{2}{*}{ Ideal Type } \\
\hline Country & Fuzzy Score & Score & $E^{*} S^{*} T$ & $E^{*} S^{*} t$ & $E^{*} s^{*} T$ & $E^{*} s^{*} t$ & \\
\hline $\mathrm{CHN}$ & 0.953 & 0.953 & 0.953 & 0.047 & 0.047 & 0.047 & \multirow{16}{*}{$\begin{array}{c}\text { Type 1: } \\
\mathrm{C}^{*} \mathrm{G}\end{array}$} \\
\hline USA & 0.821 & 0.947 & 0.821 & 0.053 & 0.179 & 0.053 & \\
\hline JPN & 0.583 & 0.683 & 0.583 & 0.317 & 0.417 & 0.317 & \\
\hline DEU & 0.548 & 0.639 & 0.548 & 0.361 & 0.452 & 0.361 & \\
\hline KOR & 0.538 & 0.554 & 0.538 & 0.446 & 0.462 & 0.446 & \\
\hline CAN & 0.534 & 0.550 & 0.534 & 0.450 & 0.466 & 0.450 & \\
\hline MEX & 0.530 & 0.573 & 0.530 & 0.427 & 0.470 & 0.427 & \\
\hline GBR & 0.526 & 0.592 & 0.526 & 0.408 & 0.474 & 0.408 & \\
\hline AUS & 0.522 & 0.529 & 0.522 & 0.471 & 0.478 & 0.471 & \\
\hline TUR & 0.520 & 0.560 & 0.520 & 0.440 & 0.480 & 0.440 & \\
\hline ITA & 0.519 & 0.574 & 0.519 & 0.426 & 0.481 & 0.426 & \\
\hline FRA & 0.517 & 0.593 & 0.517 & 0.407 & 0.483 & 0.407 & \\
\hline POL & 0.516 & 0.523 & 0.516 & 0.477 & 0.484 & 0.477 & \\
\hline ESP & 0.512 & 0.548 & 0.512 & 0.452 & 0.488 & 0.452 & \\
\hline NLD & 0.507 & 0.517 & 0.507 & 0.483 & 0.493 & 0.483 & \\
\hline BEL & 0.502 & 0.503 & 0.502 & 0.497 & 0.498 & 0.497 & \\
\hline $\mathrm{CZE}$ & 0.502 & 0.359 & 0.359 & 0.502 & 0.359 & 0.498 & \multirow{2}{*}{$\begin{array}{c}\text { Type 2: } \\
\mathrm{C}^{*} \mathrm{~g}\end{array}$} \\
\hline CHL & 0.501 & 0.477 & 0.477 & 0.501 & 0.477 & 0.499 & \\
\hline $\mathrm{CHE}$ & 0.187 & 0.504 & 0.187 & 0.187 & 0.504 & 0.496 & \multirow{2}{*}{$\begin{array}{c}\text { Type } 3 \\
\underline{\mathrm{c}^{*} \mathrm{G}}\end{array}$} \\
\hline SWE & 0.250 & 0.501 & 0.250 & 0.250 & 0.501 & 0.499 & \\
\hline ISL & 0.047 & 0.047 & 0.047 & 0.047 & 0.047 & 0.953 & \multirow{15}{*}{$\begin{array}{c}\text { Type } 4 \\
\mathrm{c}^{*} \mathrm{~g}\end{array}$} \\
\hline LVA & 0.059 & 0.060 & 0.059 & 0.059 & 0.060 & 0.940 & \\
\hline LUX & 0.066 & 0.063 & 0.063 & 0.066 & 0.063 & 0.934 & \\
\hline SVN & 0.076 & 0.067 & 0.067 & 0.076 & 0.067 & 0.924 & \\
\hline LTU & 0.076 & 0.076 & 0.076 & 0.076 & 0.076 & 0.924 & \\
\hline EST & 0.100 & 0.056 & 0.056 & 0.100 & 0.056 & 0.900 & \\
\hline SVK & 0.157 & 0.125 & 0.125 & 0.157 & 0.125 & 0.843 & \\
\hline NZL & 0.183 & 0.135 & 0.135 & 0.183 & 0.135 & 0.817 & \\
\hline IRL & 0.178 & 0.209 & 0.178 & 0.178 & 0.209 & 0.791 & \\
\hline HUN & 0.239 & 0.226 & 0.226 & 0.239 & 0.226 & 0.761 & \\
\hline DNK & 0.175 & 0.251 & 0.175 & 0.175 & 0.251 & 0.749 & \\
\hline FIN & 0.285 & 0.194 & 0.194 & 0.285 & 0.194 & 0.715 & \\
\hline PRT & 0.265 & 0.293 & 0.265 & 0.265 & 0.293 & 0.707 & \\
\hline NOR & 0.288 & 0.359 & 0.288 & 0.288 & 0.359 & 0.641 & \\
\hline ISR & 0.469 & 0.267 & 0.267 & 0.469 & 0.267 & 0.531 & \\
\hline GRC & 0.500 & 0.283 & 0.283 & 0.500 & 0.283 & 0.500 & Type 2\&4 \\
\hline AUT & 0.402 & 0.500 & 0.402 & 0.402 & 0.500 & 0.500 & Type 3\&4 \\
\hline
\end{tabular}




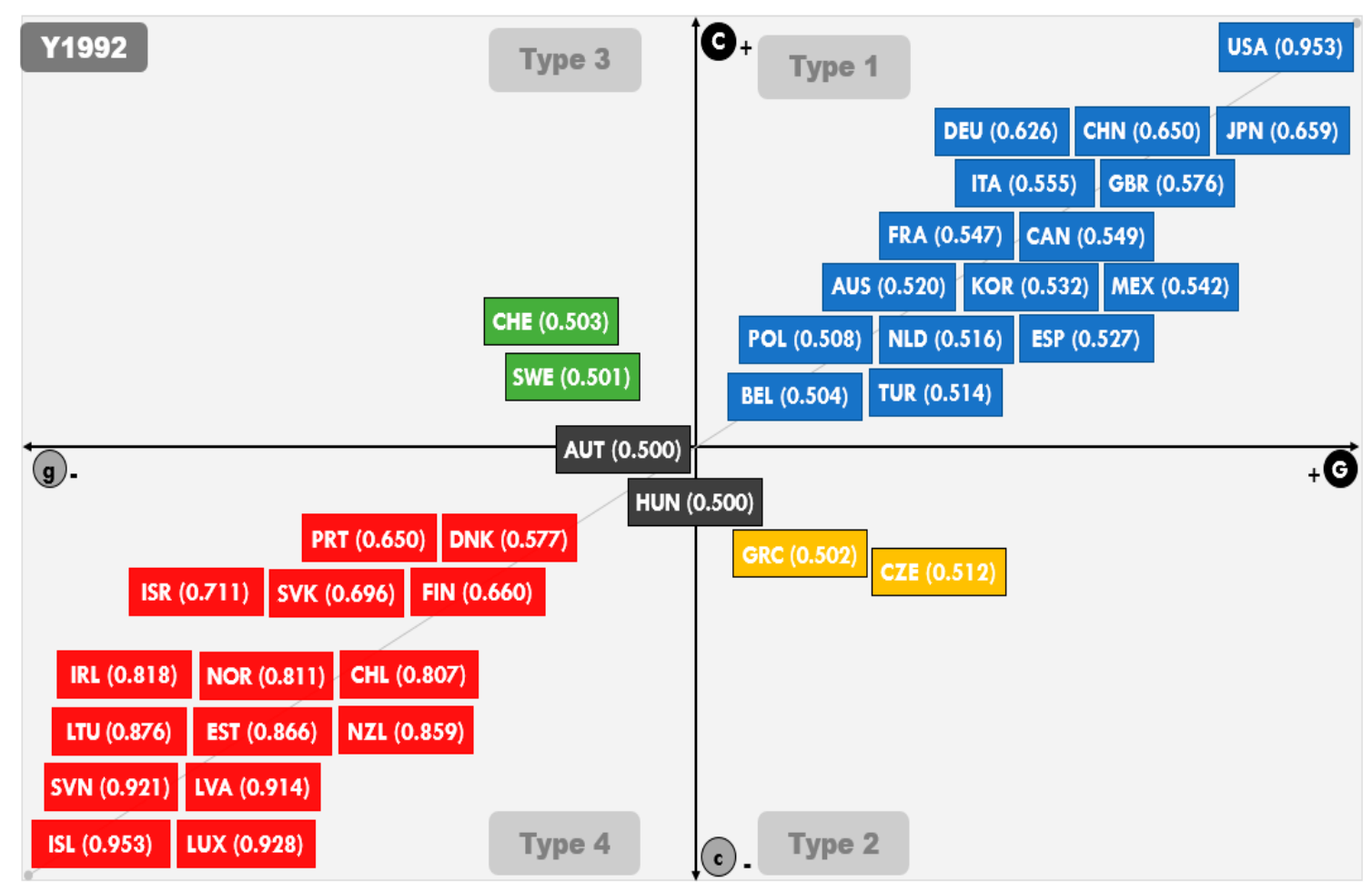

Figure 1. The Location of Link Types of the 37 Case Countries in 1992.

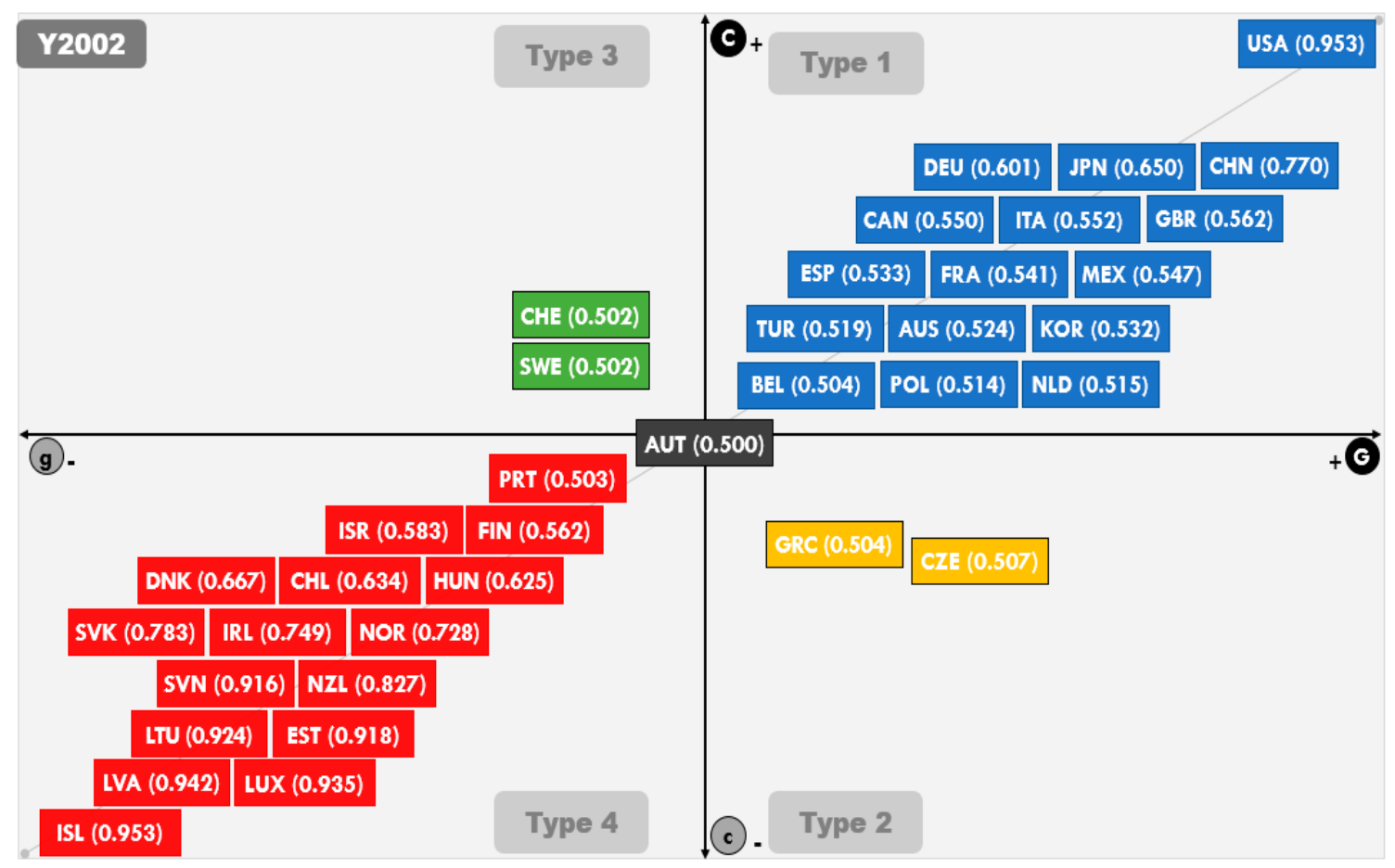

Figure 2. The Location of Link Types of the 37 Case Countries in 2002. 


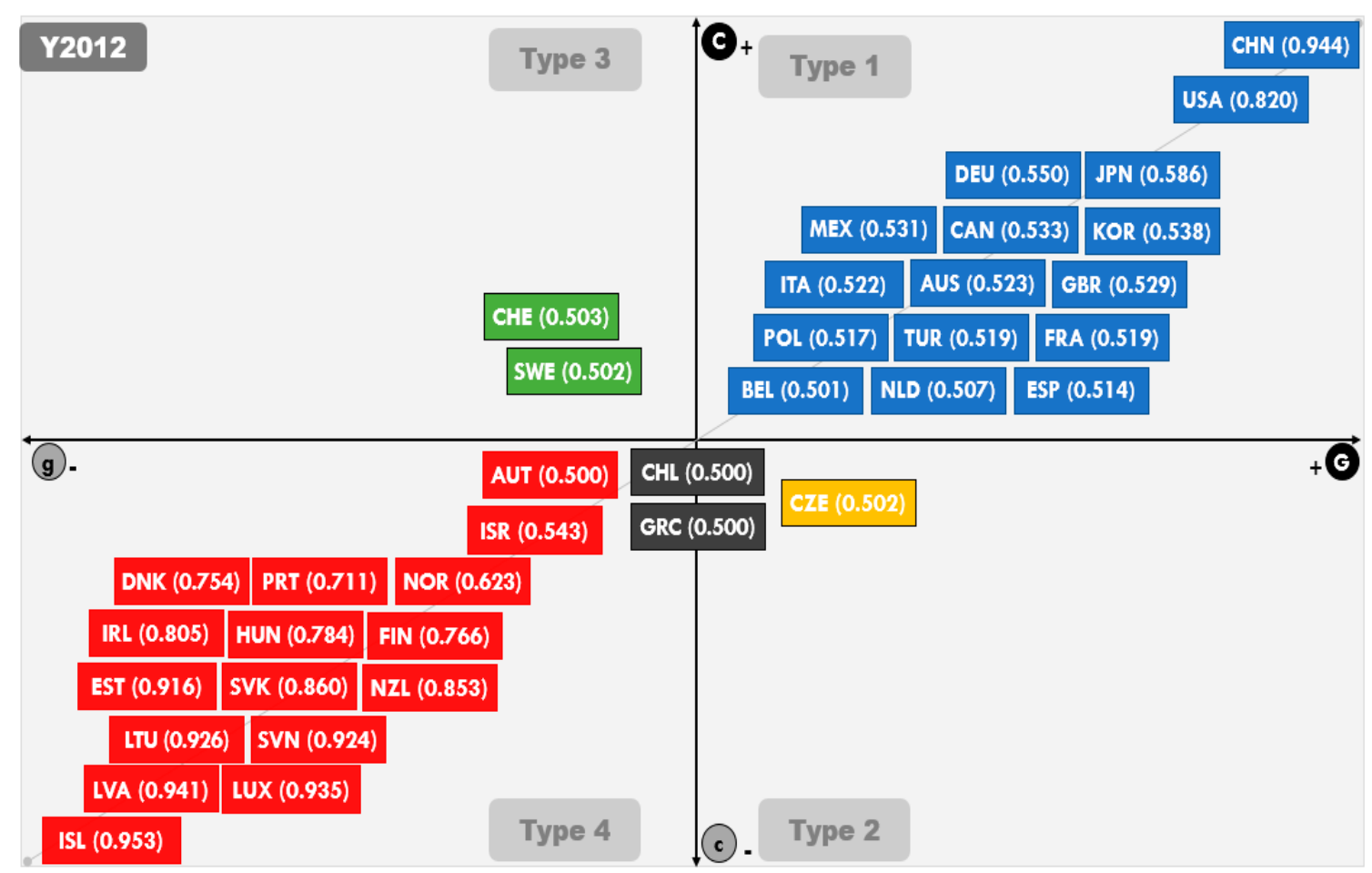

Figure 3. The Location of Link Types of the 37 Case Countries in 2012.

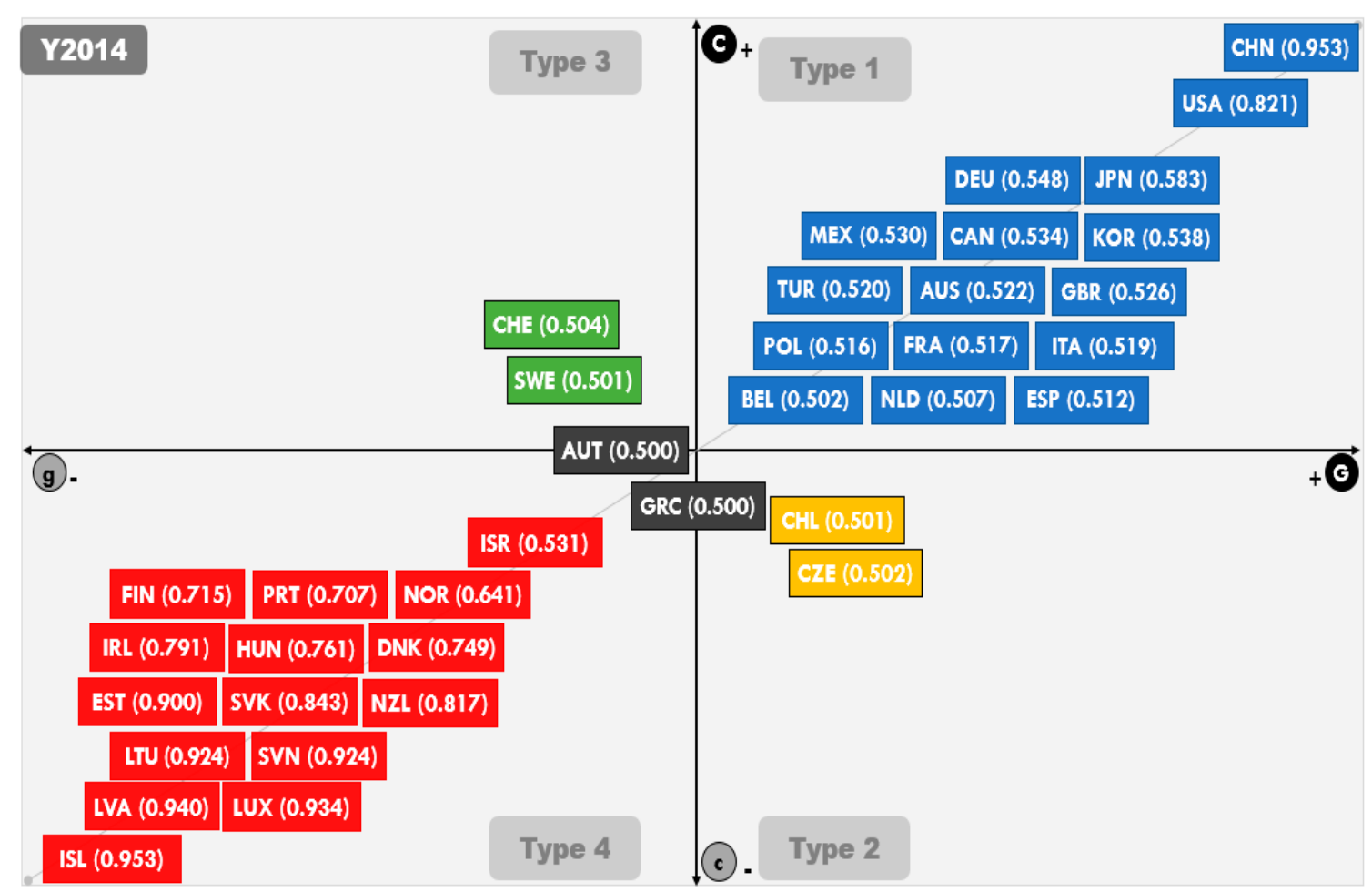

Figure 4. The Location of Link Types of the 37 Case Countries in 2014.

As a result, there is only a small number of country-specific changes (for example, Chile (Type 4 ( $c^{*}$ g: low $\mathrm{CO}_{2}$ emission and GDP)) until 2002, no type in 2012, Type 2 ( ${ }^{*} \mathrm{G}$ : low $\mathrm{CO}_{2}$ emission and high GDP) in 2014)), but the relational trajectory of the global transition to a low-carbon green economy was analyzed to not appear. In other words, a comparison of thirty-seven globally advanced countries suggests that there have been no cases of shifting to a low-carbon economy over the past 22 years: 
Type $2\left(c^{*} G\right)$ or Type $4\left(c^{*} g\right)$ affiliation. In addition, there is no change in the type of countries and no particular inflection point, according to the timing of international sustainable development and climate change conventions (1992, 2002, 2012). From Y1992 toY2002, only one country (Hungary) has changed its type, and from 12 to 14, only one country (Chile's) type has changed, as shown in Figures 1-4, above. The analysis of relative comparisons among OECD countries and China shows that the relationship between GHG and economic growth is very firmly coupled, unlike the non-combination of recent statistics.

\section{Discussion and Conclusions}

This study has attempted to explore the global trajectory of the relationship between GDP and $\mathrm{CO}_{2}$ emission from the time-series and transitional point of view (over a period of 22 years, from Y1992 to Y2014), by comparing thirty-seven country cases through the fuzzy-set ideal type analysis. Consequently, the relational trajectory of the global transition to a low-carbon green economy was analyzed to not appear, and the relationship between GDP and $\mathrm{CO}_{2}$ emissions is very firmly coupled. Namely, this study reveals that accepted conventions regarding the relationship between sustained economic growth and GHG emissions reductions are ill-founded at the international comparative level.

While the previous studies have revealed that the relationship between economic growth and environmental problems appears uncombined by country, based on the Kuznets hypothesis (EKC: 'environmental Kuznets curve') [18,28,41,42], this study found and highlighted that economic growth (GDP) and environmental problems ( $\mathrm{CO}_{2}$ emission) are tied together in a very solid path-dependent relationship by comparing the global level of the advanced countries. This paper highlights that the EKC hypothesis argues that the environmental modernization theory does have some proven aspects at the national level, but it does not work in terms of a low-carbon economy at the international comparative level. The previous empirical analytical studies relating to the EKC hypothesis also yield decoupling points (income turning point, around 13,000 30,000 USD), where the $\mathrm{CO}_{2}$ emissions stop increasing in each country (particularly developed countries) [19,43-45]. However, this study discusses and emphasizes that the existing results might be statistically significant-for example, a regression-based approach mainly used for the EKC-related researches-for each country; but, from the international and comparative point of view through the fuzzy-set ideal type analysis, countries that made a distinct shift in GDP and decoupling of $\mathrm{CO}_{2}$ (change to Type 2 or Type 4) did not appear over the 22 year periods (from Y1992 to Y2014). The combined relationship between economic growth and environmental problems has been further consolidated in advanced countries, particularly the USA, China, Japan, Germany, and so on, according to the comparative analysis of this study.

Through this 22-year time series comparison, the study reiterates the importance of relevant regulatory policies to reduce the harmful external effects of greenhouse gases. An important lesson is that unregulated markets (economics) do not deal effectively with harmful externalities, and policy alternatives that are based on the EKC hypothesis seem to overlook this lesson. The problem of climate change is not something that can be solved in the short term, but instead requires continuous effort. Therefore, there is a need for policy measures to solve the problem over the long term. It is also imperative that there be a consciousness reform on the issue of climate change.

In response to climate change, governments are tightening regulations on carbon dioxide $\left(\mathrm{CO}_{2}\right)$, while simultaneously implementing policies that reverse them. Accordingly, it is necessary to establish a coherent and feasible $\mathrm{CO}_{2}$ regulation policy. For example, it is important to more strongly expand the current certified emission reduction (CER) trading system. Emissions trading, a representative policy tool for the UNFCCC's GHG (greenhouse gas) reduction obligations, makes it possible to purchase and trade GHG emissions, like goods or assets in the market [45,46]. In addition, various innovations in the emission trading system are required to be achieved through technological innovation in the digital transformation era that is approaching a new paradigm revolution [47]. The representative examples are the industrialization of emission trading through blockchain technology and the introduction of emission trading schemes for general public areas [48,49]. 
However, a limitation of this study is that it was not able to further explore the implications of the various links between economic growth (GDP) and environmental problems $\left(\mathrm{CO}_{2}\right.$ emission) in each ideal type (Type 1, Type 2, Type 3, and Type 4) or address how countries might correct their GDP-CO 2 emission problems through both specific and alternative policy decisions

Funding: This research was funded by Gyeongsang National University.

Conflicts of Interest: The author declares no conflict of interest.

\section{References}

1. Groningen Growth and Development Centre. Maddison Project Database; University of Groningen, Groningen Growth and Development Centre: Groningen, The Netherlands, 2018.

2. Organization for Economic Co-operation and Development. Towards Green Growth; OECD: Paris, France, 2011.

3. KPMG. Future State 2030: The Global Megatrends Shaping Governments; KPMG International Cooperative: Amstelveen, The Netherlands, 2014.

4. UN Commission on Sustainable Development. The Future We Want; CSD: New York, NY, USA, 2012.

5. UK Department of Energy and Climate Change. The Carbon Plan: Delivering our Low Carbon Future; DECC: London, UK, 2011.

6. UN Economic and Social Commission for Asia and the Pacific. Low Carbon Green Growth Roadmap for Asia and the Pacific: Turning Resource Constraints and the Climate Crisis into Economic Growth Opportunities; UNESCAP: Bangkok, Thailand, 2012.

7. World Bank. Transition to a Low Carbon Economy in Poland; WB: Washington, DC, USA, 2011.

8. The White House. The U.S. Mid-Century Strategy for Deep Decarbonization; The White House: Washington, DC, USA, 2016.

9. World Commission on Environment and Development. Our Common Future; Oxford University Press: New York, NY, USA, 1987.

10. Rieu-clake, A. An Overview of Stakeholder Participation within the Danube Basin: What Current Practice and Future Challenges? In Stakeholder Participation in Transboundary Water Management-Selected Case Studies; Earle, A., Malzbender, D., Eds.; African Centre for Water Research: Cape Town, South Africa, 2006.

11. UNFCCC. Aggregate Effect of the Intended Nationally Determined Contributions: An Update; UNFCCC: New York, NY, USA, 2016.

12. Mckinsey \& Company. Pathways to Low Carbon Economy; Mckinsey \& Company: New York, NY, USA, 2009.

13. European Commission. Energy Roadmap 2050; BC: Brussels, Belgium, 2011.

14. Handrich, L.; Kemfert, C.; Mattes, A.; Pavel, F.; Traber, T. Turning Point: Decoupling Greenhouse Gas Emissions from Economic Growth; Heinrich-Boll-Stiftung: Cologne, Germany, 2015.

15. International Energy Agency. Decoupling of Global Emissions and Economic Growth Confirmed; IEA: Paris, France, 2016.

16. Pearce, D.W.; Markandya, A.; Edward, B.; Barbier, E.B. Blueprint for a Green Economy; Earthscan: Milton Park, UK, 2013.

17. Ekins, P.; Anandarjah, G.; Strachan, N. Towards a low-carbon economy: Scenarios and policies for the UK. Clim. Policy 2011, 11, 865-882. [CrossRef]

18. Agras, J.; Chapman, D.A. Dynamic Approach to the Environmental Kuznets Curve Hypothesis. Ecol. Econ. 1999, 28, 267-277. [CrossRef]

19. Canas, A.; Ferrao, P.; Conceicao, P. A New Environmental Kuznets Curve? Relationship Between Direct Material Input and Income per Capita: Evidence from Industrialised Countries. Ecol. Econ. 2003, 45, 1-13. [CrossRef]

20. International Energy Agency. $\mathrm{CO}_{2}$ Emissions from Fuel Combustion; IEA: Paris, France, 2016.

21. International Monetary Fund. World Economic Outlook 2018; IMF: Washington, DC, USA, 2018.

22. Berkeley Roundtable on the International Economy. Shaping the Green Growth Economy: A Review of the Public Debate and the Prospects for Green Growth; Green Growth Leaders Report; BRIE: Oakland, CA, USA, 2011.

23. Bataille, C.; Tu, J.; Jaccard, M. Permit sellers, permit buyers: China and Canada's roles in a global low-carbon society. Clim. Policy 2008, 8, 93-107. [CrossRef] 
24. US Energy Information Administration. Energy Outlook 2018; Office of Integrated and International Energy Analysis; EIA: Washington, DC, USA, 2018.

25. Korea Economic Research Institute. Trends and Implications of Deregulation of Greenhouse Gas Emissions and Economic Growth in Major Countries; KERI: Seoul, Korea, 2017.

26. Strachan, N.; Foxon, T.; Fujino, J. Policy implications from the Low-Carbon Society (LCS) modelling project. Clim. Policy 2008, 8, 17-29. [CrossRef]

27. Remme, U.; Blesl, M. A global perspective to achieve a low-carbon society (LCS): Scenario analysis with the ETSAP-TIAM model. Clim. Policy 2008, 8, 60-75. [CrossRef]

28. Friedl, B.; Getzner, M. Determinants of $\mathrm{CO}_{2}$ Emissions in a Small Open Economy. Ecol. Econ. 2003, 45, 133-148. [CrossRef]

29. Ragin, C.C. Fuzzy-Set Social Science; University of Chicago Press: Chicago, IL, USA, 2000.

30. Ragin, C.C. Redesigning Social Inquiry Fuzzy Sets and Beyond; University of Chicago Press: Chicago, IL, USA, 2008.

31. Choi, Y.J. Social science method: Fuzzy ideal center of analysis and factor analysis. J. Gov. Stud. 2009, 15, 307-337.

32. Schneider, C.Q.; Rohlfing, I. Case studies nested in fuzzy-set QCA on sufficiency: Formalizing case selection and causal inference. Sociol. Methods Res. 2016, 45, 526-568. [CrossRef]

33. Seok, J.E. Towards a Sustainable Welfare State: An Evaluation and Typology of OECD Countries Through the Fuzzy-set Ideal Types Analysis. Health Soc. Welf. Rev. 2014, 34, 5-35. [CrossRef]

34. Yang, J.J.; Jung, Y.R. An Empirical Research of the Underdevelopment of the Welfare State. Korean Political Sci. Rev. 2012, 46, 79-97. [CrossRef]

35. Kvist, J. Welfare reform in the Nordic countries in the 1990s: Using fuzzy-set theory to assess conformity to ideal types. J. Eur. Soc. Policy 1999, 9, 231-252. [CrossRef]

36. Kvist, J. Fuzzy set ideal type analysis. J. Bus. Res. 2007, 60, 474-481. [CrossRef]

37. Li, G.; Kou, G.; Lin, C.; Xu, L.; Liao, Y. Multi-attribute decision making with generalized fuzzy numbers. J. Oper. Res. Soc. 2015, 66, 1793-1803. [CrossRef]

38. THE WORLD BANK. WB Data- $\mathrm{CO}_{2}$ Emissions. Available online: https://data.worldbank.org/indicator/EN. ATM.CO2E.PC (accessed on 10 March 2019).

39. OECD. OECD Data-Gross Domestic Product (GDP). Available online: https://data.oecd.org/gdp/grossdomestic-product-gdp.htm (accessed on 10 March 2019).

40. Rihoux, B. Qualitative Comparative Analysis (QCA) and Related Systematic Comparative Methods: Recent Advance and Remaining Challenges for Social Science Research. Int. Sociol. 2006, 21, 679-706. [CrossRef]

41. Andreoni, J.; Levinson, A. The Simple Analytics of the Environmental Kuznets Curve. J. Public Econ. 2001, 80, 269-286. [CrossRef]

42. Mor, S.; Jindal, S. Estimation of Environmental Kuznets Curve and Kyoto Parties: A Panel Data Analysis. Int. J. Comput. Eng. Manag. 2012, 15, 5-9.

43. Yoon, J.Y.; Song, J.M. Empirical Study on the Impact of Urban Economic Growth on the Quality of Environment: With a focus on 95 cities in the world. J. Korea Plan. Assoc. 2015, 50, 145-158. [CrossRef]

44. Unruh, G.C.; Moomaw, W.R. An Alternative Analysis of Apparent EKC-Type Transitions. Ecol. Econ. 1998, 25, 221-229. [CrossRef]

45. Choi, C.I.; Kim, J.H. An International Comparative Study on the Relationship between Economic Growth and Environmental Pollution: Testing the existence of EKC in $\mathrm{CO}_{2}$. J. Korea Plan. Assoc. 2006, 41, 153-166.

46. Kim, S.; Choi, J.K. Emission Trading System as Market-based Regulatory Alternative. Korean Soc. Public Adm. 2016, 26, 165-194.

47. UK Government Office for Science. Distributed Ledger Technology: Beyond Block Chain; UK Government Office for Science: London, UK, 2016.

48. Organization for Economic Co-operation and Development. Towards Global Carbon Pricing, Direct and Indirect Linking of Carbon Markets; OECD: Paris, France, 2010.

49. Limpaitoon, T.; Chen, Y.; Oren, S. The Impact of Imperfect Competition in Emission Permits Trading on Oligopolistic Electricity Markets. Energy J. 2014, 35, 145-166. [CrossRef]

(C) 2020 by the author. Licensee MDPI, Basel, Switzerland. This article is an open access article distributed under the terms and conditions of the Creative Commons Attribution (CC BY) license (http://creativecommons.org/licenses/by/4.0/). 